\title{
Prevalence and Morphological Characterization of Cheilospirura hamulosa, Diesing, 1861 (Nematoda: Acuarioidea), from Partridges in Iran
}

\author{
Maryam Ebrahimi, ${ }^{1}$ Soheila Rouhani, ${ }^{1}$ Iraj Mobedi, ${ }^{2,3}$ Ali Rostami, ${ }^{1}$ \\ Hoshang Khazan, ${ }^{1}$ and Mohammad Bagher Ahoo $^{3}$ \\ ${ }^{1}$ Department of Parasitology and Mycology, School of Medicine, Shahid Beheshti University of Medical Sciences, Tehran, Iran \\ ${ }^{2}$ Department of Medical Parasitology and Mycology, School of Public Health, Tehran University of Medical Sciences, Tehran, Iran \\ ${ }^{3}$ Department of Parasitology, Faculty of Veterinary Medicine, University of Tehran, Tehran, Iran
}

Correspondence should be addressed to Soheila Rouhani; srouhanil1@sbmu.ac.ir

Received 17 July 2015; Revised 18 October 2015; Accepted 22 October 2015

Academic Editor: Bernard Marchand

Copyright ( 92015 Maryam Ebrahimi et al. This is an open access article distributed under the Creative Commons Attribution License, which permits unrestricted use, distribution, and reproduction in any medium, provided the original work is properly cited.

\begin{abstract}
This study reports data on the prevalence, morphology, and morphometry of the nematode Cheilospirura hamulosa on the basis of light and stereoscopic microscopy and also camera lucida. Specimens were recovered after necropsies of 100 partridges (Alectoris chukar) from Taleqan County in Alborz Province, Iran. The prevalence of C. hamulosa in partridges was of $30 \%$ with a mean intensity of 3.9 and range of infection of 1-12. The mean length and width of females were $17.5 \pm 2.14$ and $0.39 \pm 0.04 \mathrm{~mm}$, while those of males were $12.2 \pm 0.67$ and $0.3 \pm 0.06 \mathrm{~mm}$, respectively. The characteristic digitiform tail was observed in females, and the unequal spicules, caudal alae, and ten pairs of caudal papillae were seen in males. The taxonomic characteristic longitudinal cordons and muscular and glandular oesophagus were observed in both sexes. Ratio between cordons and body length in males and females was $1: 1.33$ and $1: 1.68$, respectively. Ratio between long and short spicules in males was $1: 2.3$. The average size of embryonated eggs was $51.25 \times 29.5 \mu \mathrm{m}$. In the present study, C. hamulosa (Nematoda: Acuarioidea) is recorded for the first time from partridges in Iran. Therefore, the morphological characters described in this study will be useful in the future diagnostic and taxonomic studies of Acuarioidea family.
\end{abstract}

\section{Introduction}

The parasitic nematode Cheilospirura hamulosa, "Diesing, 1861" (syn. Acuaria hamulosa), is a species of Acuariidae family and etiological agent of cheilospirurosis in birds such as chickens, turkeys, pigeons, and guinea fowls $[1,2]$. Cheilospirura hamulosa has cylindrical body with two triangular lips and 4 cuticular cordons that extend near posterior extremity. Male worms have two distinctly unequal and dissimilar spicules. Female worm tails are curved ventrally and digitiform $[3,4]$.

The C. hamulosa is located under gizzard cuticle mainly in koilin or muscular wall of the host $[1,2]$. This nematode has indirect life cycle. The grasshoppers (Melanoplus,
Oxyanitidula, and Spathosternum parasinifrum), beetles, and weevils are intermediate hosts for $C$. hamulosa and birds acquire their infections by eating contaminated arthropods containing infective third-stage larvae [1]. Due to its high pathogenicity in poultry, the C. hamulosa has veterinary and public health importance. Cheilospirura hamulosa can cause several complications such as granulomas and nodules that lead to anemia, impotence, and mortality in chickens [2]. Cheilospirura hamulosa may cause zoonosis and has been recovered from a nodule on the conjunctiva of a Filipino farmer [5]. The previous studies in rural areas of Iran indicated that the infection of this worm is common among free-range chickens [6], whereas there is no published data on partridges in Iran. The main goal of the present study 
was to survey prevalence of Cheilospirura hamulosa infection in partridges (Alectoris chukar) using morphological-based methods, in Taleqan County of Iran.

\section{Materials and Methods}

The study was conducted in Taleqan County. This area is located in Alborz Province and its height is $1900 \mathrm{~m}$ above the sea level. Latitude and longitude of Taleqan are 36 degrees $15^{\prime} \mathrm{N}$ and 50 degrees $46^{\prime} \mathrm{E}$, respectively.

One hundred partridges were collected from Taleqan mountainous region between 2011 and 2013. Every year from the end of September to the beginning of February a license is issued by the Environment Protection Agency (EPA) of Iran for hunting partridges. Every hunter has permission to hunt the maximum of three partridges weekly. For this research, the gizzard of each partridge was removed from the alimentary tract and delivered to the helminthology laboratory of Shahid Beheshti University of Medical Sciences. The gizzards were examined macroscopically and then dissected in a $0.85 \% \mathrm{NaCl}$ solution (normal saline) to remove cuticle. Worms were visible to the naked eye. The worms were rinsed in normal saline and fixed in Alcohol-Glycerin (70\% Alcohol, $50 \mathrm{~mL}$; Glycerin, $50 \mathrm{~mL}$ ) solution. Nematodes were elucidated with acetic acid and phenol, mounted in Canada balsam. Helminthes were counted and identified under light microscopy (Zeiss, Germany) and stereoscopic microscope (Zeiss, Germany) and traced by camera lucida (Zeiss, Germany). The morphological identification of the nematodes to the species level was done according to methods described by Skrjabin et al. [9].

\section{Results}

3.1. Prevalence of C. hamulosa. Out of a total of 100 partridges examined, the prevalence of C. hamulosa was 30\% with a mean intensity of $3.9 \%$ and range of infection of 1-12. A total of 116 worms were recovered from partridges. Among the recovered helminthes, $60.3 \%$ were female and $39.7 \%$ male. The specimens of $C$. hamulosa were found free under the gizzard cuticle, partially or fully burrowed in the walls (Figure 1). Microscopic description was based on 10 adult worms, five males and five females (Table 1).

3.2. Male ( $n=5$, Except When Otherwise Indicated). The average length of adult males was $12.2 \pm 0.67 \mathrm{~mm}$ and their average width was $0.3 \pm 0.06$. Buccal cavity was 0.21 long, 0.019 wide $(n=1)$. Muscular oesophagus was $0.37-0.38$ $(0.375, n=2)$ long. Glandular oesophagus was 1.6-2.4 (2, $n=2)$ long. Length of total oesophagus was 1.97-2.78 (2.37, $n=2)$. The mean of cordons length was $9.2 \pm 0.28$, ratio between cordons and body length was $1: 1.33$ (Figure 2, (A1)(A3)), long spicule slender was $1.44 \pm 0.08 \mathrm{~mm}$ in length, short spicule shaped like a chopping knife was $0.62 \pm 0.11 \mathrm{~mm}$ long, and ratio between long and short spicules was $1: 2.3$. The ratio between mean of long and short spicules length and body length were $0.11 \mathrm{~mm}$ and $0.04 \mathrm{~mm}$, respectively. The mean length of caudal alae was $0.42 \pm 0.02$ and its width

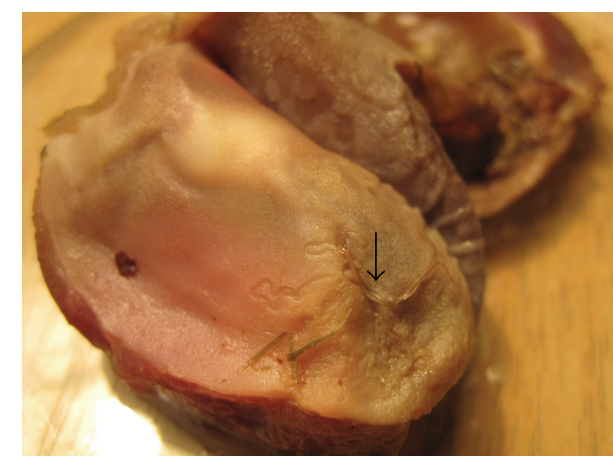

FIgURE 1: Cheilospirura hamulosa under the gizzard cuticle.

was $0.32 \pm 0.02$, with tail $0.43 \mathrm{~mm}$ long $(n=1)$. In each worm there were ten pairs of caudal papillae: three couples were observed in precloacal, two pairs in adcloacal, and five couples in postcloacal (Figure 2, (B1)-(B3)).

3.3. Female ( $n=5$, Except When Otherwise Indicated). The mean length and width of females were $17.5 \pm 2.14$ and $0.39 \pm 0.04 \mathrm{~mm}$, respectively. Buccal cavity was 0.22 long and 0.028 wide $(n=1)$. Muscular oesophagus was $0.29-$ $0.75(0.45, n=3)$ long. Glandular oesophagus was $2.1-2.7$ $(2.3, n=3)$ long. Length of total oesophagus was 2.39-3.05 $(2.82, n=3)$. The mean of cordon length was $12.96 \pm 0.72$, and ratio between cordons and body length was $1: 1.68$. The females were amphidelphic, and their vulva is located slightly posterior to the middle of the body at $2.29 \pm 0.92$ from the posterior end, circular sphincter $0.064 \times 0.065$, tail $0.44(n=$ 1) long (Figure 3, (A1)-(A2) and (B1)-(B2)). Embryonated eggs were $0.045-0.055$ (0.051) long and 0.028-0.03 (0.029) wide (Figure 4).

\section{Discussion}

The nematode C. hamulosa reported herein is reported for the first time from partridges in Iran. Studies on this nematode in Iran only was carried out in native fowls. The partridge (Alectoris chukar) is the most important bird hunted in Iran. In the present study, prevalence of C. hamulosa in the partridge was $30 \%$ with a mean intensity of $3.9 \%$ and range of infection of 1-12.

The reported prevalence of this nematode by Menezes et al. [2] in Brazil was $14.3 \%$ in ring-necked pheasants (Phasianus colchicus) with a mean intensity and range of infection of 1.5, 1-2, respectively. In domestic chickens (Gallus g. domesticus), the prevalence, mean intensity, and range of infection were $26.7 \%, 4$ and 1-12, respectively [2]. A 2-year study in Kashmir, India, on the prevalence of the nematode $C$. hamulosa in indigenous fowl has shown an overall prevalence of $3.5 \%(17 / 478)$ [10]. The prevalence of C. hamulosa in guinea fowls (Numida meleagris galeata Pallas) from Ghana and chickens in Zimbabwe and Cuba was 37.8\%, 46.6\%, and $84.6 \%$, respectively [11-13]. These results are higher than our finding. The reported prevalence of C. hamulosa on 


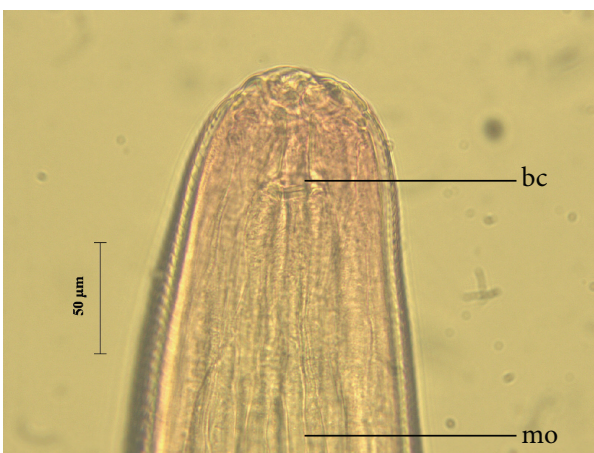

(A1)

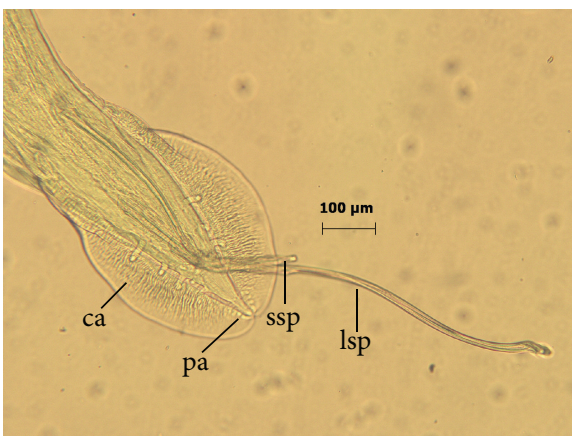

(B1)

(a)

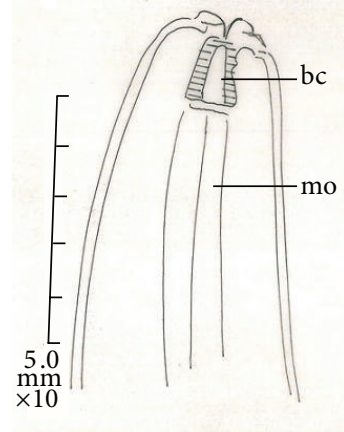

(A2)

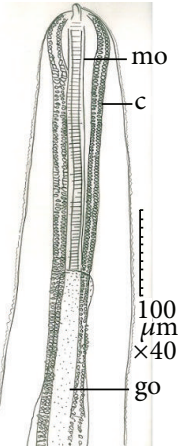

(A3)

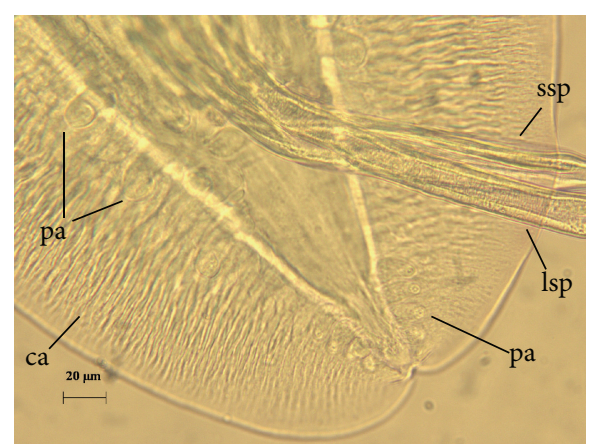

(B2)

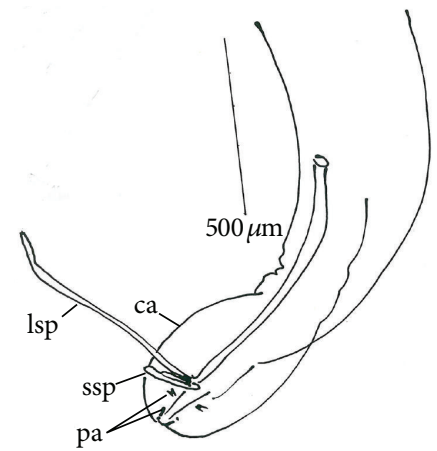

(B3)

(b)

Figure 2: Male of Cheilospirura hamulosa; light micrographs and camera lucida. (A1) Enlarged view of the anterior region, buccal cavity (bc), muscular oesophagus (mo); (A2) anterior end, lateral view, buccal cavity (bc), muscular oesophagus (mo); (A3) anterior end, sublateral view, muscular oesophagus (mo), glandular oesophagus (go), and cordon (c); (B1) and (B2) male posterior end, showing small (ssp) and large (lsp) spicules, caudal alae (ca), and caudal papillae (pa); (B3) posterior end of male, lateral view, papillae (pa), long spicule (lsp), short spicule (ssp), and caudal alae (ca).

native fowls from Golestan Province in north of Iran was 4\% which is significantly lower than our result, because the study population is completely different from our study [6].

The nematodes of the genus Acuaria (Cheilospirura) are parasitic among different families of birds and they are located under the koilin layer usually in the cardiac or pyloric regions [2]. Also in our study the specimens of $C$. hamulosa were found under the gizzard cuticle, partially or fully burrowed in the walls of the organ (Figure 1).
Most of the reported lengths for male and female $C$. hamulosa are within the range of 9-14 and 15-25, respectively $([3,14]$ and $[1,7,8]$ ) (Table 1$)$. In this study, male worms were smaller than the female worms in average body length, overall cordon, glandular oesophagus, and muscular oesophagus length (Table 1). Moreover, in our study, the long spicules were smaller and the length of short spicules was longer compared with previous studies reported by Cram $[1,3]$, Yamaguti [7], and Gomes et al. [8] (see Table 1 for 


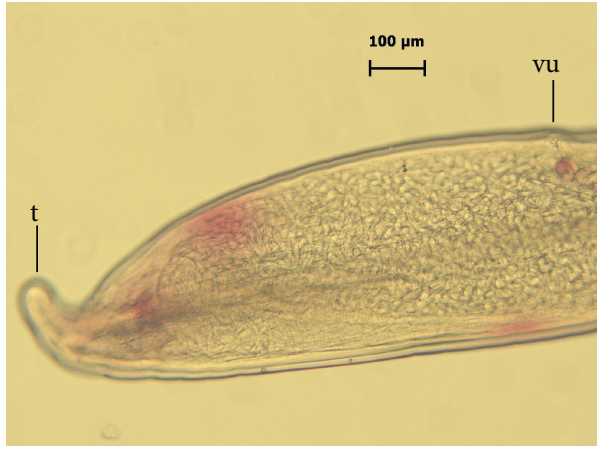

(A1)

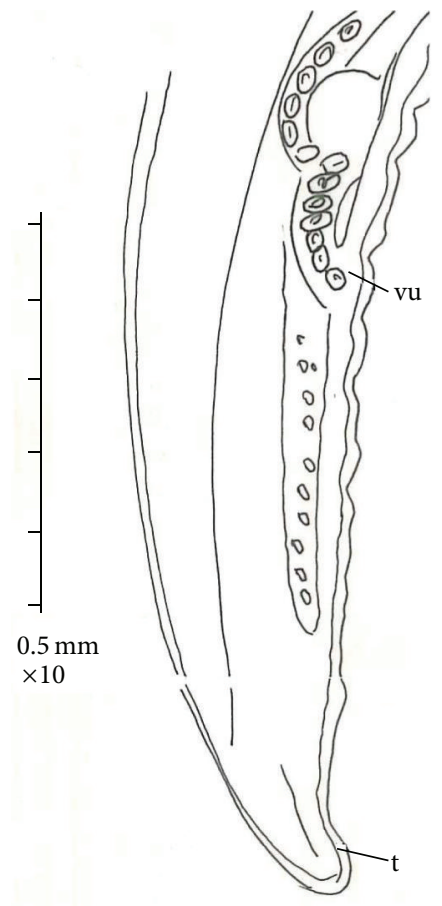

(B1)

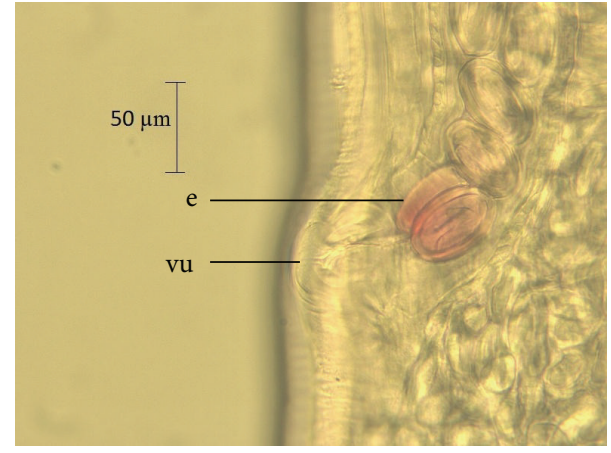

(A2)

(a)

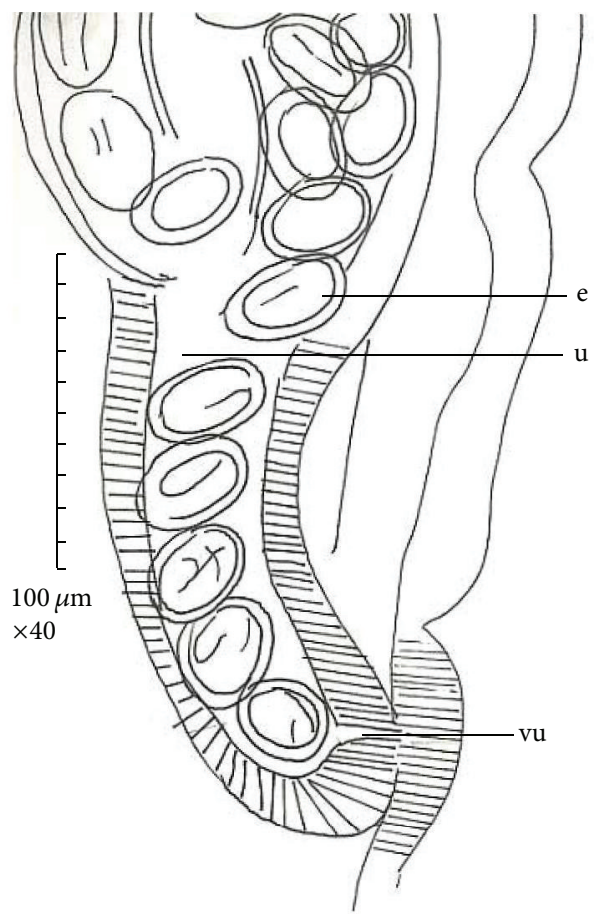

(B2)

(b)

Figure 3: Female of Cheilospirura hamulosa; light micrographs and camera lucida. (A1) Female posterior end, showing vulva (vu), tail (t); (A2) enlarged view of the female posterior region, showing vulva (vu), embryonated eggs (e); (B1) and (B2) posterior end of female, vulva (vu), utri (u), egg (e), and tail (t).

comparison). In our study, average length of male worms was higher than those reported by Gomes et al. [8]. In our study, the female worms were smaller in maximum body length than those described by Cram and Yamaguti $[3,7]$ but still were bigger than those described by Gomes et al. [8]. The female of $C$. hamulosa in our study had smaller muscular and glandular oesophagus than those reported by Gomes and Yamaguti $[7,8]$, whereas values obtained for the length of tail and egg size were bigger compared to two studies mentioned above (Table 1). We observed 10 pairs of papillae in C. hamulosa as reported by Cram [3] and Gomes et al. [8]; however, in the precloacal region, 2 pairs of papillae were unclear (Figure 2, (B1)-(B3)).
Due to the significant pathogenic effects of these nematodes (Cheilospirura spp.) in poultry and wild bird population and very limited prevalence data of these helminthes in Iran, further study will be needed on different aspects of Acuarioidea family including pathogenesis and their prevalence in other avian species.

\section{Conclusions}

In the present study, we report for the first time the isolation and morphological characterization of Cheilospirura hamulosa from partridges in Iran. The morphological characters 
TABLE 1: Comparison of Cheilospirura hamulosa body parts from partridges of Iran with those of previous reports (mm).

\begin{tabular}{|c|c|c|c|c|}
\hline & Cram, 1931 [1] & Yamaguti, 1954 [7] & Gomes et al., 2004 [8] & This study, 2014 \\
\hline Male & - & $n=1$ & $n=4$ & $n=5$ \\
\hline Body, length (mm) & $9-13$ & 13.6 & 9.54 & $11.18-13(12.22)$ \\
\hline Body, width (mm) & $0.3-0.32$ & 0.32 & 0.28 & $0.25-0.4(0.3)$ \\
\hline Cordons, length & $7.2-8.8$ & - & - & $9-9.6(9.2)$ \\
\hline Buccal cavity & - & $0.24 \times 0.03$ & - & $0.21 \times 0.019^{*}$ \\
\hline Muscular oesophagus, length & - & $0.91 \times 0.098$ & 0.67 & $0.37-0.38(0.375)^{* *}$ \\
\hline Glandular oesophagus, length & - & $2.55 \times 0.154$ & 2.21 & $1.6-2.4(2)^{* *}$ \\
\hline Tail, length & $0.416-0.488$ & 0.56 & - & $0.43^{*}$ \\
\hline Long spicule (lsp) & $1.6-1.8$ & 2.4 & $1.48-1.74(1.60)$ & $1.4-1.6(1.44)$ \\
\hline $\begin{array}{l}\text { The ratio between lsp length and } \\
\text { body length }\end{array}$ & - & 0.17 & 0.16 & 0.11 \\
\hline short spicule (ssp) & $0.2-0.22$ & 0.18 & $0.22-0.26(0.22)$ & $0.5-0.8(0.62)$ \\
\hline $\begin{array}{l}\text { The ratio between ssp length and } \\
\text { body length }\end{array}$ & - & 0.01 & 0.02 & 0.04 \\
\hline $\begin{array}{l}\text { Pairs of postcloacal } \\
\text { Papillae }\end{array}$ & 6 & 3 & 5 & 5 \\
\hline Female & - & $n=2$ & $n=5$ & $n=5$ \\
\hline Body, length (mm) & $15-22$ & $24-25$ & $9.7-23.09(15.36)$ & $16-20(17.5)$ \\
\hline Body, width (mm) & $0.4-0.65$ & $0.46-0.5$ & 0.40 & $0.35-0.45(0.39)$ \\
\hline Cordons, length & $10-15$ & - & - & $12.5-13.8(12.96)$ \\
\hline Buccal cavity, length & - & $0.33 \times 0.047-0.057$ & - & $0.23 \times 0.028^{*}$ \\
\hline Muscular oesophagus, length & - & $1.26-1.3$ & 0.82 & $0.29-0.75(0.45)^{* * *}$ \\
\hline Glandular oesophagus, length & - & $4.2-4.5$ & 2.83 & $2.1-2.7(2.3)^{* * *}$ \\
\hline Tail, length & $0.42-0.59$ & 0.28 & 0.33 & $0.44^{*}$ \\
\hline $\operatorname{Egg}(\mu \mathrm{m})$ & $40 \times 27$ & $39-45 \times 24-26$ & $36 \times 22$ & $51.25 \times 29.5$ \\
\hline
\end{tabular}

${ }^{*}$ Measurements from one male and female only.

** Measurements from two males only.

*** Measurements from three females only.

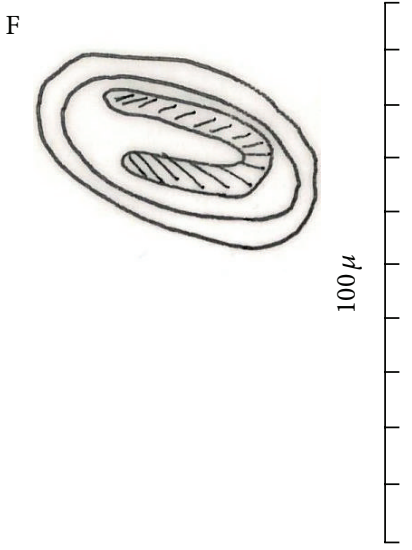

Figure 4: Camera lucida of embryonated egg.

described in this study will be useful in the future diagnostic and taxonomic studies of Acuarioidea family.

\section{Conflict of Interests}

None of the above authors have any conflict of interests.

\section{Acknowledgments}

The authors thank Dr. Shoreh Miller for English editing of this paper and Mr. Naser Bagheri for sending the alimentary tract of partridges.

\section{References}

[1] E. B. Cram, "Developmental stages of some nematodes of the Spiruroidea parasitic in poultry and game birds," Technical Bulletin 227, United State Deprtment of Agriculture, 1931.

[2] R. C. Menezes, R. Tortelly, D. C. Gomes, and R. M. Pinto, "Pathology and frequency of Cheilospirura hamulosa (Nematoda, Acuarioidea) in Galliformes hosts from backyard flocks," Avian Pathology, vol. 32, no. 2, pp. 151-156, 2003.

[3] E. B. Cram, "Bird parasites of the nematode suborders strongylata, ascaridata, and spirurata," Bulletin of the United States National Museum, vol. 140, pp. 1-465, 1927. 
[4] S. Rouhani, M. Ebrahimi, A. Rostami, and S. H. Fallahi, "Effective, appropriate and simple culture, egg hatching and cryopreserving of the nematode Cheilospirura hamulosa," British Poultry Science, vol. 55, no. 6, pp. 846-849, 2014.

[5] R. Muller, Worms and Human Disease, CABI Publishing, 2nd edition, 2002.

[6] A. Eslami, P. Ghaemi, and S. Rahbari, "Parasitic infections of free-range chickens from Golestan province, Iran," Iranian Journal of Parasitology, vol. 4, no. 3, pp. 10-14, 2009.

[7] S. Yamaguti, "Parasitic worms mainly from Celebes. Part 10. Nematodes of birds and mammals," Acta Medica Okayama, vol. 9, pp. 134-135, 1954.

[8] D. C. Gomes, R. C. Menezes, J. J. Vicente, R. M. Lanfredi, and R. M. Pinto, "New morphological data on Cheilospirura hamulosa (Nematoda, Acuarioidea) by means of bright-field and scanning electron microscopy," Parasitology Research, vol. 92, no. 3, pp. 225-231, 2004.

[9] K. I. Skrjabin, A. A. Sobolev, and V. M. Ivashkin, Essentials of Nematodology. XIV. Spirurata of Animals and Man and the Diseases They Cause, Acuarioidea, part 3, Akademii Nauk SSSR, Moscow, Russia, 1965.

[10] S. T. Salam, M. S. Mir, S. Shahnaz, and R. A. Khan, "Prevalence and the associated lesions of Cheilospirura (Acuaria) hamulosa in the indigenous chicken of Kashmir Valley, India," Journal of Parasitology, vol. 95, no. 6, pp. 1436-1439, 2009.

[11] J. Hodasi, "The helminth parasites of the helmet guinea fowl (Numida meleagris galeata pallas) in Ghana," Bulletin of Animal Health and Production in Africa, vol. 24, pp. 81-87, 1976.

[12] E. Cruz, "Comunicacion sobre una considerable extensión de invasión por Cheilospirura hamulosa en aves ponedoras (1966)," Ciencia y Técnica en la Agricultura. Veterinaria, vol. 3, pp. 67-69, 1966.

[13] J. Jansen and V. Pandey, "Observations on helminth parasites of domestic fowls in Zimbabwe," Zimbabwe Veterinary Journal, vol. 20, no. 1, pp. 15-17, 1989.

[14] H. D. Srivastava, "Studies on the helminth parasites of Indian poultry. Part III. The occurrence of two spirurid stomach worms in fowls," Journal of Veterinary Science and Animal Husbandry, vol. 9, no. 2, pp. 225-227, 1939. 

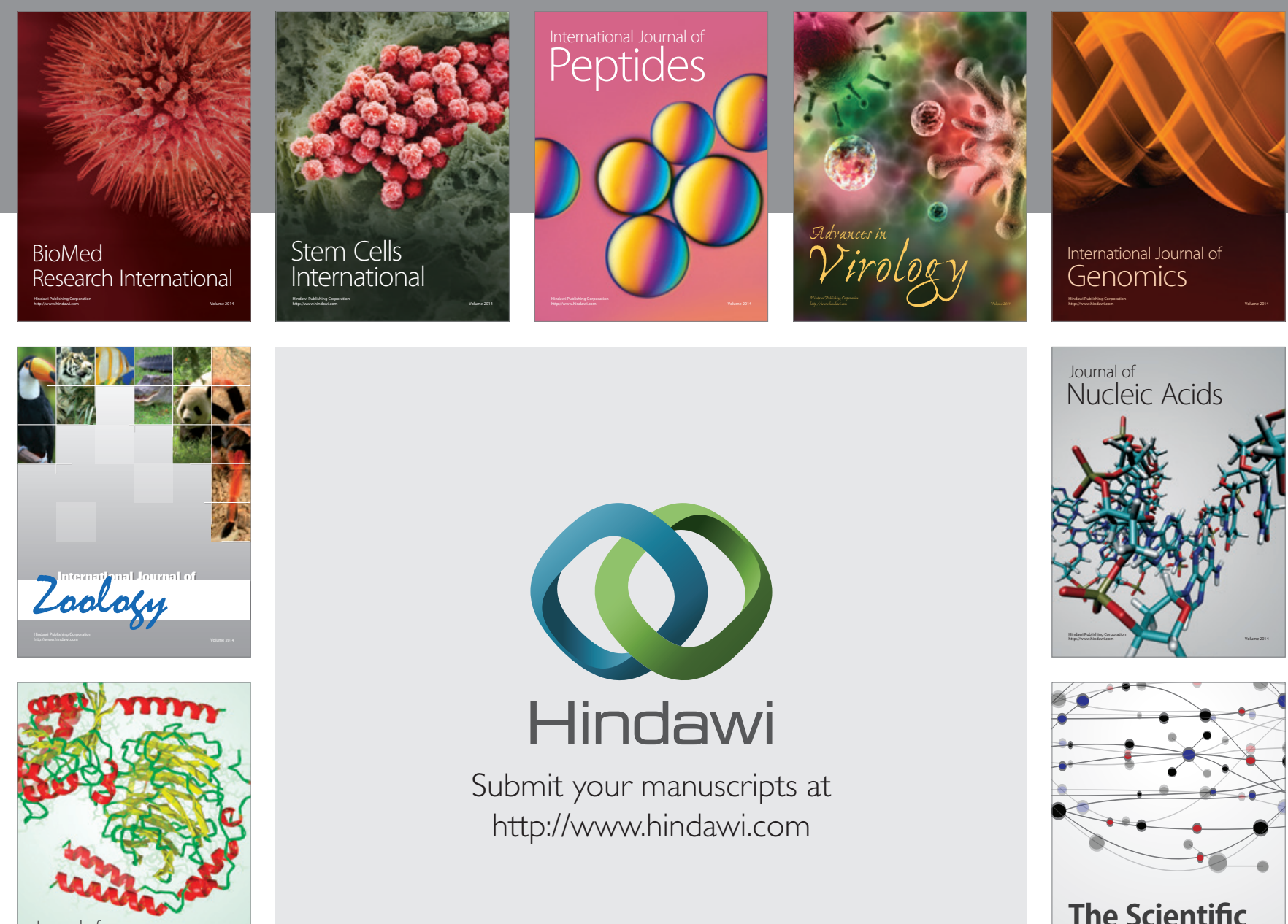

Submit your manuscripts at

http://www.hindawi.com

Journal of
Signal Transduction
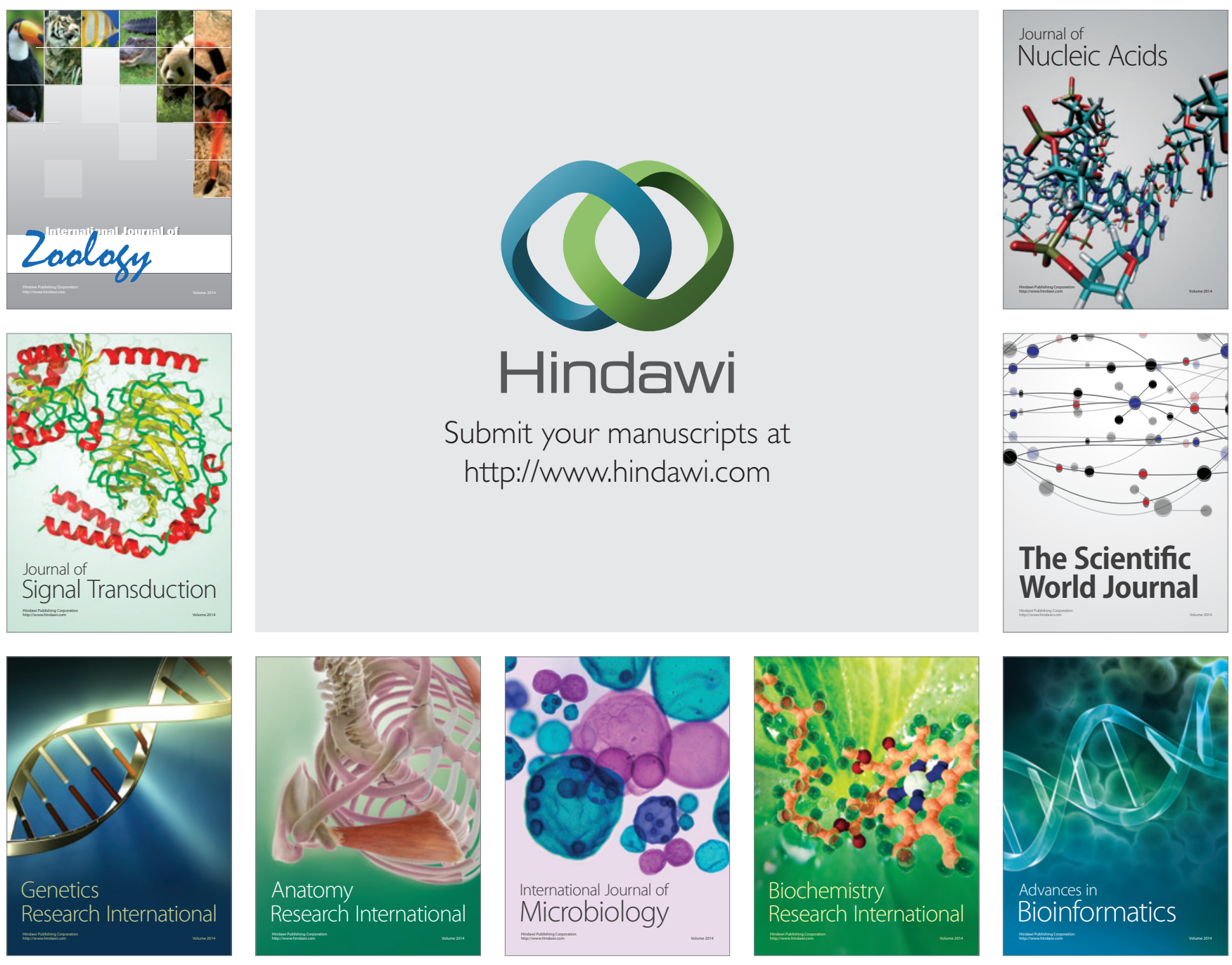

The Scientific World Journal
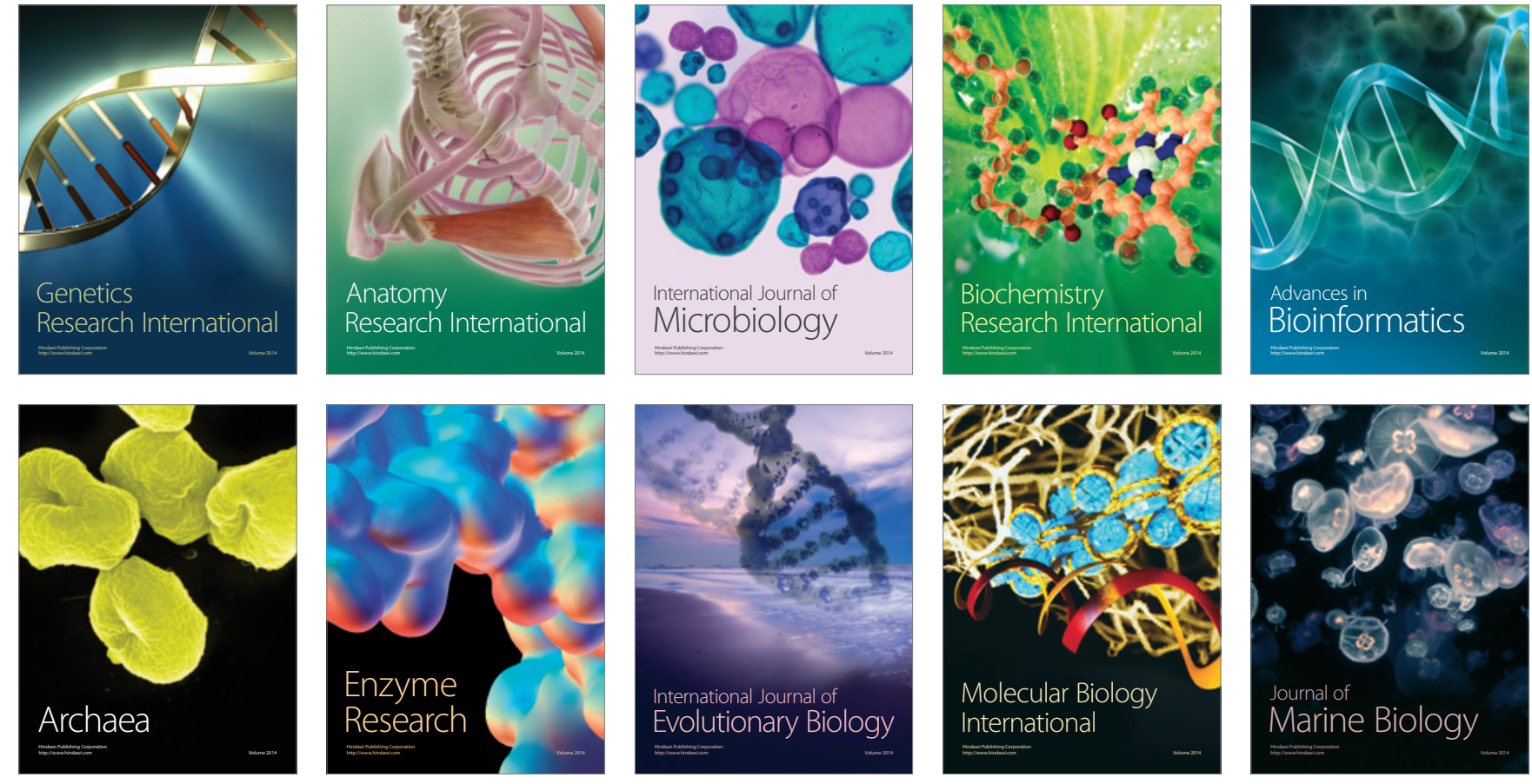